\title{
What we have learned from risk charts?
}

\section{Eren Arslan' \& Serap Erdine ${ }^{\dagger 1}$}

IIstanbul University Cerrahpasa Medical Faculty, Internal Medicine Department, 34452 Fatih, Istanbul †Author for correspondence: Istanbul University Cerrahpasa Medical Faculty, Cardiology Department = Tel.: +90 2122652564 m Fax: +902122652568 m eserdine@superonline.com

Evaluation of: Sehestedt T, Jeppesen J, Hansen TW et al.: Risk stratification with the risk chart from the European Society of Hypertension compared with SCORE in the general population. J. Hypertens. 27, 2351-2357 (2009). Risk factor assessment is an important issue in preventing and treating cardiovascular diseases. Three widely used risk charts: the Framingham, Systemic Coronary Risk Evaluation and the European Society of Hypertension/European Society of Cardiology charts, are discussed, and a recent study by Sehestedt et al. comparing systemic coronary risk evaluation and the European Society of Hypertension/European Society of Cardiology chart, is also evaluated in this article.

\section{Summary of methods \& results}

Danish individuals $(\mathrm{n}=1344)$ without known diabetes mellitus, prior stroke or myocardial infarction, not receiving cardiovascular, antidiabetic or lipid-lowering medications and with a blood pressure higher than optimal $(\geq 120 / 80 \mathrm{mmHg}$ ) were enrolled in the study [1]. Their traditional risk factors and subclinical organ damage were measured. The individuals were followed for 12.8 years and fatal and nonfatal cardiovascular (CV) events were obtained. The European Society of Hypertension (ESH) risk chart classified 368 patients as high-risk compared with the Systemic Coronary Risk Evaluation (SCORE); however, the two risk evaluation methods were in agreement that $89 \%$ of the patients required antihypertensive treatment and they had similar sensitivities (79 vs $79 \%$ ) and specificities ( 46 vs $50 \%$ ), as well as positive (14 vs $15 \%$ ) and negative (95 vs 96\%) predictive values for composite end point.

\section{Importance of global risk assessment}

The direct relationship between blood pressure (BP) and cerebrovascular and CV diseases [2] is supported by the increasing volume of data. It was also realized that hypertension rarely presented alone; most hypertensive patients had additional risk factors, such as diabetes mellitus, insulin resistance, hyperlipidemia and/or cigarette smoking [3-7]. The high possibility of one risk factor clustering with another risk factor(s) multiplies CV disease risk. The concept of total (global) $\mathrm{CV}$ risk was born from recognition of risk factors' coexistence $[8]$ and indicates the absolute risk to have $\mathrm{CV}$ events in 10 years time [9]. When the global risk concept is well understood it will be easier to predict concomitant diseases in a patient, especially in patients who are asymptomatic or whose $\mathrm{BP}$ is normal or high-normal. However, in high-risk individuals, because of subclinical organ damage and additional risk factors, concomitant diseases are underdiagnosed. Proper diagnosis and early treatment of this hidden group will prevent progression of cerebrovascular and $\mathrm{CV}$ events.

An increasing number of patients who have CV risk factors from mild-to-severe led physicians and investigators to stratify patients according to these risk factors. Stratification delineates the BP threshold to initiate antihypertensive treatment, the intensity of treatment, combination therapy administration and the need for other drugs from other classes (antiplatelet or antilipidemic) [9].

\section{Methods to assess global risk}

There are three widely used methods to assess global CV risk: Framingham Heart Study (FHS), SCORE and European Society of Cardiology/European Society of Hypertension (ESC/ESH) guidelines [10].

The FHS created multivariable mathematical functions to assess the risk of coronary heart disease over 10 years. These variables (risks) were gender, age, BP, total cholesterol, LDLcholesterol, HDL-cholesterol, cigarette smoking and diabetes [11].

The SCORE project obtained data from 12 European cohort studies and was designed to develop a risk-scoring system to evaluate $\mathrm{CV}$ risk in European clinical practice [12].

The last approach originated from the 1999 WHO/International Society of Hypertension guidelines [13] and this was widened to utilize ESH/ESC guidelines [9]. This approach focused on target organ damage and associated risk factors in $\mathrm{CV}$ health.
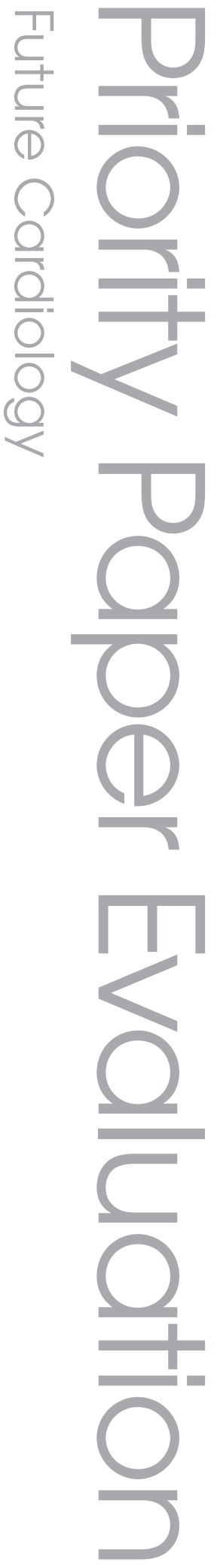

future medicine $_{\text {mes }}$ fs 


\section{Critical approach to risk charts}

According to the ESH 2007 guidelines [9], there are some common limitations in risk charts. For example, the exposure period to a risk factor or disease is not taken into account. Variables such as physical inactivity and stress, which are strictly associated with CV events, did not gain enough importance in all three risk charts.

The SCORE and Framingham risk charts have been the most commonly compared approaches. The FHS was limited to white, middle class individuals from Framingham, MA, USA, so validation of this risk chart to other ethnic groups needs to be evaluated [13]. The Framingham risk chart did not consider diabetic patients as high-risk, which other charts did. SCORE was based on traditional risk factors (gender, smoking status, $\mathrm{BP}$ and total cholesterol) in calculating a 10-year risk of fatal CV events and is representative of the European population [12]. ESH guidelines criticize SCORE since young adults (especially women) are not able to reach treatment thresholds even though they have more than one risk factor. At the same time, older adults ( $>70$ years) can reach a high-risk status with only a small risk increment. This situation makes physicians focus on older patients. However, during their youth, young adults who are not treated will face many more risk factors in middle age, and thus they may reach an irreversible high-risk status. This situation can be remedied by making relative risk-based assessments when treatment initiation and intensity are discussed. ESH guidelines offer subclinical organ damage evaluation (microalbuminuria, left ventricular hypertrophy, carotid atherosclerosis and abnormalities in pulse wave velocity) in addition to classical risk factors [8]. As mentioned in a reappraisal of European guidelines [14], subclinical organ damage evaluation is useful to optimize the decision regarding treatment initiation, intensity and goals. In hypertensive patients, the presence of subclinical organ damage usually brings $\mathrm{CV}$ risk into the high range. Subclinical organ damage should be assessed at screening and also during treatment because treatment-induced changes in organ damage provide information regarding the benefit of treatment and protection against $\mathrm{CV}$ events. Despite being beneficial, subclinical organ damage assessment (especially those requiring new technology) can be expensive and compared with routine tests.

\section{Discussion}

Compared with ESH, SCORE underestimates total $C V$ risk $[1,15]$ and this is attributed to detailed assessment of subclinical organ damage. Sehestedt et al. found that patients were reclassified and carried from lower to higher risk categories with subclinical organ damage assessment [7,16,17]. Even though a more detailed evaluation occurred in $\mathrm{ESH}$, they both stated similar sensitivity, specificity and positive and negative predictive values. Surprisingly, SCORE and ESH/ESC guidelines recommended antihypertensive treatment in almost the same patients, despite the much more detailed assessment in the latter approach.

\section{Future perspective}

Early diagnosis, significant lifestyle changes and treatment are major determinants in reducing $\mathrm{CV}$ and cerebrovascular events. It is important to use risk charts in clinical practice for early detection. Comparing risk charts in further research will add to our knowledge and demonstrate different perspectives.

\section{Financial \& competing interests disclosure \\ The authors have no relevant affiliations or financial involvement with any organization or entity with a financial interest in or financial conflict with the sub- ject matter or materials discussed in the manuscript. This includes employment, consultancies, honoraria, stock ownership or options, expert testimony, grants or patents received or pending, or royalties. \\ No writing assistance was utilized in the production of this manuscript.}

\section{Executive summary}

- The relationship between blood pressure and cerebrovascular and cardiovascular diseases is a well-known phenomenon.

- In cardiovascular prevention, early detection and stratification of patients according to their risks is important.

- The three most used risk charts are the Framigham, Systemic Coronary Risk Evaluation (SCORE) and European Society of Hypertension/European Society of Cardiology (ESH/ESC) charts. The Framingham Heart Study created multivariable mathematica functions to assess the risk of coronary heart disease over 10 years. The SCORE project obtained data from 12 European cohort studies and was designed to develop a risk scoring system to evaluate cardiovascular risk in European clinical practice. ESH/ESC originated from the $1999 \mathrm{WHO} /$ International Society of Hypertension guidelines and was widened by ESH/ESC guidelines focused on target organ damage and associated risk factors in cardiovascular health.

- Detailed evaluation of patients by subclinical organ damage examination with ESH risk charts carries patients into a higher risk status than the SCORE risk chart. Both risk charts were found to be almost equally sensitive and specific, and have similar positive and negative predictive values. 


\section{Bibliography}

1. Sehestedt T, Jeppesen J, Hansen TW et al.: Risk stratification with the risk chart from the European Society of Hypertension compared with SCORE in the general population. J. Hypertens. 27, 2351-2357 (2009).

2. MacMahon S, Peto R, Cutler J et al:: Blood pressure, stroke, and coronary heart disease. Part 1, prolonged differences in blood pressure: prospective observational studies corrected for the regression dilution bias. Lancet 335(8692), 765-774 (1990).

3. Kannel WB: Risk stratification in hypertension: new insights from the Framingham study. Am. J. Hypertens. 13(Suppl. 1), S3-S10 (2000).

4. Thomas F, Rudnichi A, Bacri AM, Bean K, Guize L, Benetos A: Cardiovascular mortality in hypertensive men according to presence of associated risk factors. Hypertension 37(5), 1256-1261 (2001).

5. Mancia G, De BG, Dominiczak A et al.: 2007 guidelines for the management of arterial hypertension: the Task Force for the Management of Arterial Hypertension of the European Society of Hypertension (ESH) and of the European Society of Cardiology (ESC). J. Hypertens. 25, 1105-1187 (2007).
6. Mancia G: Comparing methods for assessing cardiovascular risk. J. Hypertens. 27, 2342-2343 (2009).

7. Kannel WB, McGee D, Gordon T: A general cardiovascular risk profile: the Framingham Study. Am. J. Cardiol. 38, 46-51 (1976).

8. Conroy RM, Pyorala K, Fitzgerald AP et al:: Estimation of ten-year risk of fatal cardiovascular disease in Europe: the SCORE project. Eur. Heart J. 24, 987-1003 (2003).

9. 1999 World Health Organization International Society of Hypertension guidelines for the management of hypertension. Guidelines subcommittee. J. Hypertens. 17, 151-183 (1999).

10. Mancia G, Laurent S, Agabiti-Rosei E et al.: Reappraisal of European guidelines on hypertension management: a European Society of Hypertension (ESH) task force document. J. Hypertens. 27, 905-922 (2009).

11. Lengele JP, Vinck WJ, De Plaen JF, Persu A: Cardiovascular risk assessment in hypertensive patients: major discrepancy according to ESH and SCORE strategies. J. Hypertens. 25, 757-762 (2007).

12. Leoncini G, Ratto E, Viazzi F et al.: Global risk stratification in primary hypertension: the role of the kidney. J. Hypertens. 26, 427-432 (2008).
13. Viazzi F, Parodi D, Leoncini G et al.: Optimizing global risk evaluation in primary hypertension: the role of microalbuminuria and cardiovascular ultrasonography. J. Hypertens. 22, 907-913 (2004).

14. Mancia G, Laurent S, Agabiti-Rosei E et al:: Reappraisal of European guidelines on hypertension management: a European Society of Hypertension (ESH) task force document. J. Hypertens. 27, 2121-2158 (2009).

15. Lengele JP, Vinck WJ, De Plaen JF, Persu A: Cardiovascular risk assessment in hypertensive patients: major discrepancy according to ESH and SCORE strategies. J. Hypertens. 25, 757-762 (2007).

16. Leoncini G, Ratto E, Viazzi F et al:: Global risk stratification in primary hypertension: the role of the kidney. J. Hypertens. 26, 427-432 (2008).

17. Viazzi F, Parodi D, Leoncini G et al.: Optimizing global risk evaluation in primary hypertension: the role of microalbuminuria and cardiovascular ultrasonography. J. Hypertens. 22, 907-913 (2004). 